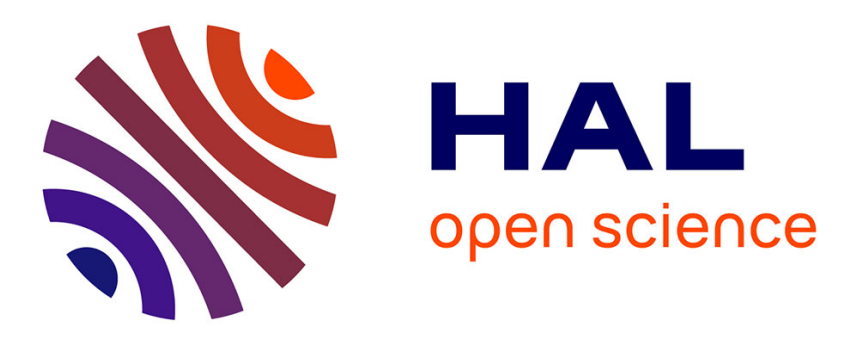

\title{
A method for computing the VOR multipath error-Comparisons with in-flight measurements
}

Ludovic Claudepierre, Rémi Douvenot, Alexandre Chabory, Christophe Morlaas

\section{- To cite this version:}

Ludovic Claudepierre, Rémi Douvenot, Alexandre Chabory, Christophe Morlaas. A method for computing the VOR multipath error-Comparisons with in-flight measurements. EuCAP 2016, 10th Eu-

ropean Conference on Antennas and Propagation , Apr 2016, Davos, Switzerland. 10.1109/EuCAP.2016.7481546 . hal-01331140

\section{HAL Id: hal-01331140 \\ https://hal-enac.archives-ouvertes.fr/hal-01331140}

Submitted on 13 Jun 2016

HAL is a multi-disciplinary open access archive for the deposit and dissemination of scientific research documents, whether they are published or not. The documents may come from teaching and research institutions in France or abroad, or from public or private research centers.
L'archive ouverte pluridisciplinaire $\mathbf{H A L}$, est destinée au dépôt et à la diffusion de documents scientifiques de niveau recherche, publiés ou non, émanant des établissements d'enseignement et de recherche français ou étrangers, des laboratoires publics ou privés. 


\title{
A Method for Computing the VOR Multipath Error - Comparisons with In-flight Measurements
}

\author{
Ludovic Claudepierre, Rémi Douvenot, Alexandre Chabory, and Christophe Morlaas \\ TELECOM-EMA, ENAC, Toulouse Univ., Toulouse, France, remi.douvenot@ recherche.enac.fr
}

\begin{abstract}
This work presents the validation of a modelling method for the characterisation of the VOR error in the presence of large scatterers. More specifically, wind turbines are considered because their increasing number makes their modelling a topical problem. Here, the electromagnetic perturbation due to the wind turbines is addressed by a method hybridising parabolic wave equation and physical optics. The VOR receiver is considered such that the overall method gives an estimation of the VOR error. This method is validated by comparisons with in-flight measurements performed in the same location before and after the erection of a wind farm.
\end{abstract}

Index Terms-VOR error, parabolic equation, physical optic, hybridisation, multipath, electromagnetic modelling, wind turbines.

\section{INTRODUCTION}

For air transport navigation, VHF Omnidirectional Range (VOR) systems are crucial: they give to aircraft their direction with respect to North. However, this information can be deteriorated by nearby obstacles, which yield multipaths. Signals coming from unwanted directions are processed by the onboard VOR receiver, which modify the on-board displayed bearing.

Today, the air transport authority delivers approvals for the construction of buildings in the vicinity of VORs [1]. Their rules are very restrictive, and wind turbine industrialists request looser regulations. The method presented here could be used for delivering case-by-case approvals, for wind turbines and other buildings.

The simulation method presented here follows three objectives: 1/ the simulation can be performed on a standard computer in reasonable time, $2 /$ the output of the model is the VOR error, which renders the method easily interpretable for the air transport community, and $3 /$ the model gives a prediction of the VOR error with a good accuracy. The VOR error expression requires both the amplitude and the phase of the direct and multipath signals [2]. Therefore, a good balance between computation time and accuracy is required with both amplitude and phase of the multipaths.

Many types of simulation methods have been proposed during the last decade. The uniform theory of diffraction has been proposed [3], [4]. This method is accurate but is memory intensive for complex scenes. More recently, models involving parabolic equation (PE) and physical optics (PO) have been developed [5], [6]. The work presented here is based on these latter. Models based on the RCS [7], [8] or using the knifeedge model [9] have also been developed. They propose fast computations of the field scattered by wind turbines. However, the simplifications underlying these models are important, and the VOR error cannot be obtained since the phase is not available. These methods are interesting for rough calculations, but cannot give precise results.

Finally, the method preferred here is the hybridisation between parabolic equation (PE) [10] and physical optics (PO) [11] to calculate the multipaths. The hybridisation method is detailed in Claudepierre et al. [12]. The main advantages are to considered the antenna radiation pattern and the relief between the VOR antenna and the wind turbines. Moreover, the ground composition is taken into account. The major drawback is that 3D effects are neglected. The relevancy to use PO for the simulation of the field scattered by the wind turbines has been demonstrated by Claudepierre et al. [13].

The simulation method is briefly presented in section II. In section III, the measurement campaign is introduced, and the choice of the relevant data to validate the simulator is presented. Finally, in section IV, the simulator is validated by comparisons to in-flight measurements and used for a deeper analysis of the scenario.

\section{Simulation Method}

The modelling of the computation follows four steps, as illustrated in Figure 1: first, the field is calculated on the scatterers using a PE method. One PE simulation is performed for each scatterers (except if they are aligned). Second, the currents on the scatterers are calculated from the PE incident field with an hybridisation process detailed in [12] that takes into account the dielectric parts of the wind turbines. Third, the field radiated by the currents is computed on the receiver by PO. Finally, a VOR error given below is applied by considering the multipaths and the direct field analytically computed.

Note that the incident field on each scatterer is calculated by neglecting their mutual interactions. Indeed, in the case of wind turbines, their mutual influence has been demonstrated to be negligible at the VOR frequency [14].

The block diagram of the method is given in Figure 2. From the geometry of the scenery, the antenna properties, and the composition of the scatterers, the VOR error can be calculated at the required observation points. One PE calculation and one PO simulation is performed per scatterer. Finally, following [2], the VOR error is calculated by combining the scattered 


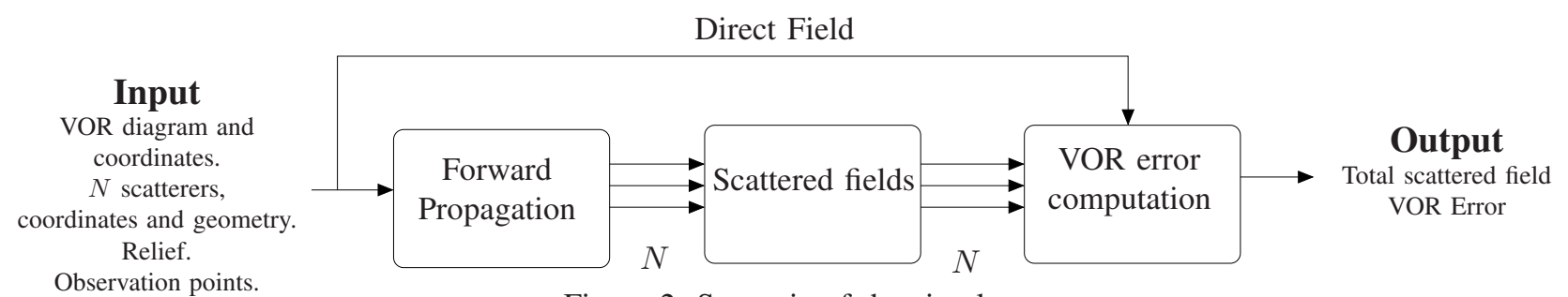

Figure 2: Synoptic of the simulator.

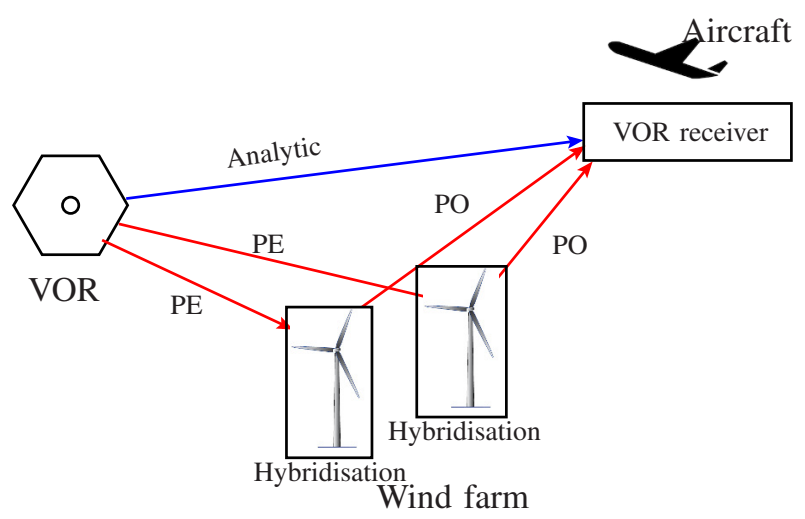

Figure 1: Overview of the simulator

fields and the direct field, by

$$
\varepsilon^{c}=\tan ^{-1}\left(\frac{-\sum_{n=1}^{N} a_{n} \cos \left(\theta_{n}\right) \sin \left(\varphi_{n}\right)}{1+\sum_{n=1}^{N} a_{n} \cos \left(\theta_{n}\right) \cos \left(\varphi_{n}\right)}\right)
$$

where $a_{n}, \theta_{n}$, and $\varphi_{n}$ are the amplitude, the phase, and the azimuth of the $n^{\text {th }}$ multipath, respectively. These values are normalised by the amplitude, the phase, and the azimuth of the direct signal. This equation is valid for the conventional VOR. Another expression depending on the same parameters is available for the Doppler VOR [2].

\section{MEASUREMENT CAMPAign}

\section{A. Description of the measurement campaign}

The case of nine wind turbines (ENERCON E-70) erected at about $5 \mathrm{~km}$ from the conventional VOR of Boulogne-sur-Mer (France) is studied (Figure 3). The frequency is $113.8 \mathrm{MHz}$. The relief between the VOR and wind turbines is accounted and a dielectric ground $\left(\epsilon_{r}=25, \sigma=0.02\right)$ is considered.

The wind turbines, represented by yellow circles in Figure 3 , are composed by a metallic conic mast (height $=98 \mathrm{~m}$, top diameter $=2 \mathrm{~m}$, and bottom diameter $=7.5 \mathrm{~m}$ ), a hub modelled by a metallic rectangular parallelepiped $(4 \times 11 \times 4 \mathrm{~m})$, and blades modelled by 2 parallel dielectric slabs (length $=35 \mathrm{~m}$, maximum width $=1 \mathrm{~m}$, thickness $=44 \mathrm{~mm}$, and $\epsilon_{r}=5$ ) with $0.65 \mathrm{~m}$ spacing. A metallic rod representing the lightning protection $($ diameter $=10 \mathrm{~mm}$ ) is placed between them. This

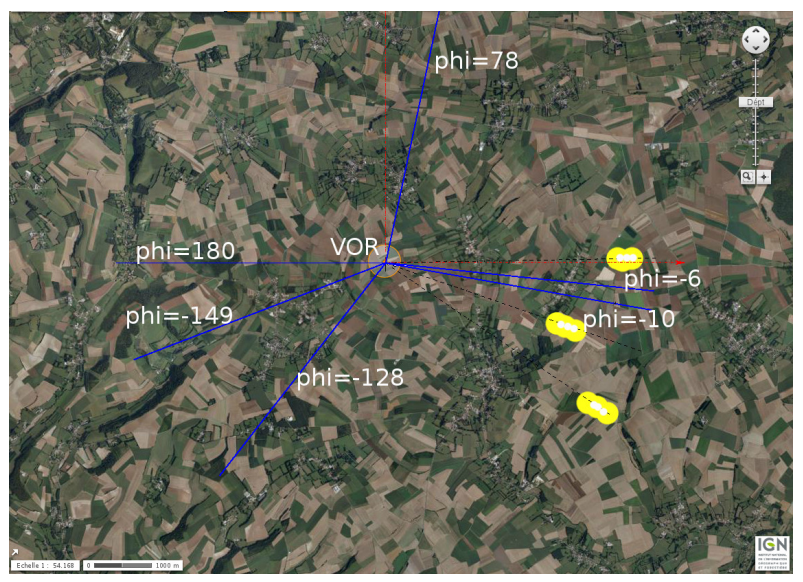

Figure 3: Wind farm at $5 \mathrm{~km}$ from the VORC of Boulognesur-Mer (France) and measurement radials (blue lines).

wind turbine model has been validated by Claudepierre et al. [13].

The exact aircraft positions during the flight measurements have been given by an on-board GPS receiver. Moreover, the exact orientations of the hubs during the measurement are also available.

The flight inspections have been performed along six radials (blue lines in Figure 3) at three different times: without wind turbines in May 2009, with only the masts erected in July 2012, and with the complete wind turbines in November 2012.

\section{B. Selection of the relevant measurements}

A first work before validating the simulation method with measurements is to assure the relevancy of the comparison. In this paper, this process is illustrated with two radials $\varphi=$ $-10^{\circ}$ and $\varphi=78^{\circ}$.

The VOR error for the three measurements campaigns on the two radials $\varphi=-10^{\circ}$, and $\varphi=78^{\circ}$ are plotted with respect to distance in Figures 4 and 5, respectively.

An error already exists in the first measurement campaign without the wind turbines. This error due to the surrounding environment is not negligible: up to $0.6^{\circ}$ of error on $\varphi=78^{\circ}$ and up to $1^{\circ}$ of error on $\varphi=-10^{\circ}$. The mean and variance of the absolute error are given in table $\mathrm{I}$ for the three measurement campaigns corresponding to no wind turbines, only the masts, and the complete wind turbines, respectively.

On the radial $\varphi=78^{\circ}$, no significantly change in the mean and variance of the error is observed. It implies that 


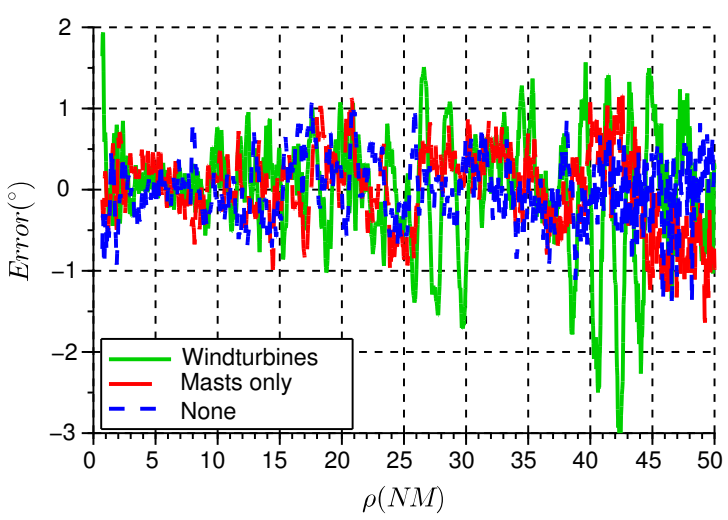

Figure 4: VOR error measured during the flight inspection campaigns without the wind turbines (blue), with the masts only (red), and with the complete wind turbines (green). The radial is $\varphi=-10^{\circ}$.

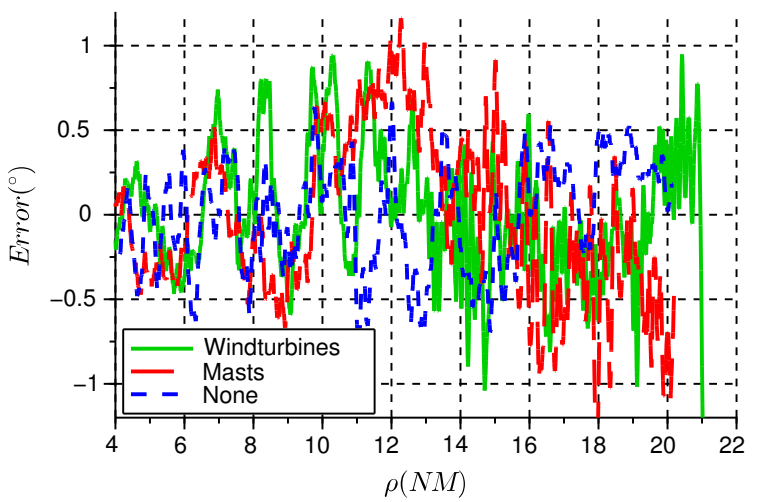

Figure 5: VOR error measured during the flight inspection campaigns w/o the wind turbines (blue), with the masts only (red), and with the complete wind turbines (green). The radial is $\varphi=78^{\circ}$.

the VOR error induced by the wind turbines is hidden by the surrounding disturbances. Comparing simulations with these data is irrelevant. By contrast, on the radial $\varphi=-10^{\circ}$, the mean and the variance of the error significantly increase with the erection of the wind turbines. Therefore, only the radial $\varphi=-10^{\circ}$ can be used for the validation. This result can be geometrically interpreted from Fig. 3. On the radial $\varphi=-10^{\circ}$, the wind turbine impact is more significant because the aircraft overflies the wind farm, which is not the case on the radial $\varphi=78^{\circ}$.

\section{RESUlts}

\section{A. Validation of the simulation method}

The simulation method is validated by comparison with the VOR error measured along the radials $\varphi=-10^{\circ}$. The simulated and measured VOR errors due to the masts only are plotted in Figures 6 with respect to distance. In the same way, the simulated and measured VOR error for the complete wind

\begin{tabular}{c|c|c|c|c}
\hline \multicolumn{2}{c|}{ Windturbines } & None & Masts only & Complete \\
\hline \multirow{2}{*}{ Rad. $78^{\circ}$} & Mean & 0.26 & 0.37 & 0.27 \\
& Variance & 0.028 & 0.069 & 0.056 \\
\hline \multirow{2}{*}{ Rad. $-10^{\circ}$} & Mean & 0.31 & 0.40 & 0.53 \\
& Variance & 0.056 & 0.09 & 0.25 \\
\hline
\end{tabular}

Table I: Mean and variance of the absolute value of the VOR error for the three flight inspection measurements.

turbines are plotted in Figure 7. For a distance greater than $20 \mathrm{NM}$, there is a good agreement between the measurements and the simulations. Below $20 \mathrm{NM}$, the disturbance due to the surroundings prevails, see Figure 4.

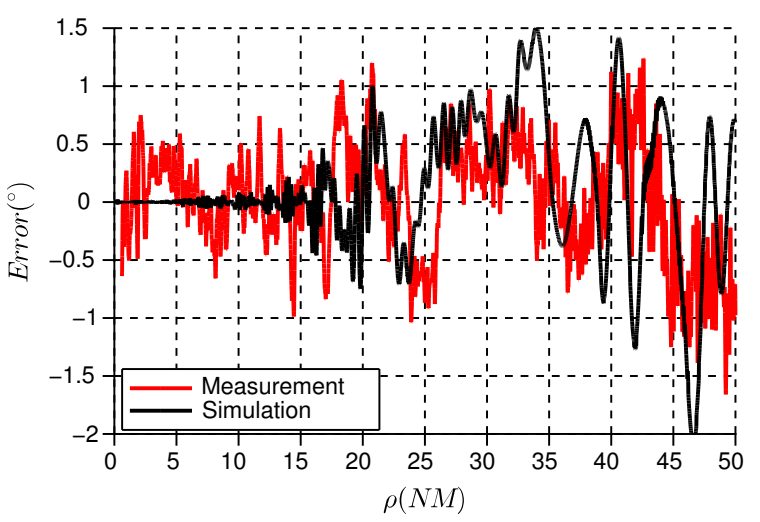

Figure 6: VOR error due to the wind turbine masts measured (red) and simulated (black) on the radial $\varphi=-10^{\circ}$.

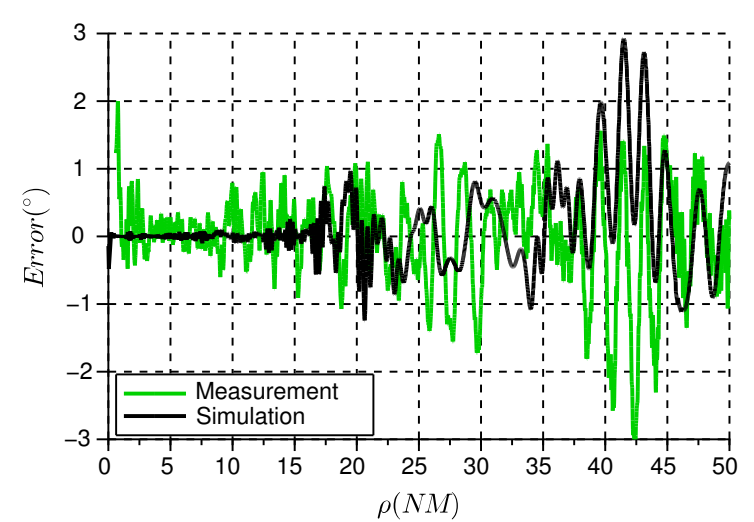

Figure 7: VOR error due to the wind turbines measured (red) and simulated (black) on the radial $\varphi=-10^{\circ}$.

Some inaccuracies still remain. Some fast variations are not correctly modelled, and a sign difference sometimes appear. It may come from the VOR receiver which is in reality more complicated than equation (1) used for the simulation. However, the simulation gives an accurate approximation of the error due to the wind turbines. Thus, the simulator is considered validated. More validations are presented in [12]. 


\section{B. Quantification of the contribution of each part of the wind turbines}

To obtain more information about the influence of wind turbines on the VOR error, the simulation method is able to isolate the contributions of every part of the wind turbines in a post-processing step. For instance, the simulation result presented in Figure 7 is detailed in this section to give a better understanding of the scattering phenomena involved.

The respective contributions of the wind turbines blades, hubs, and masts to the VOR error are plotted in Figure 8 with respect to distance.

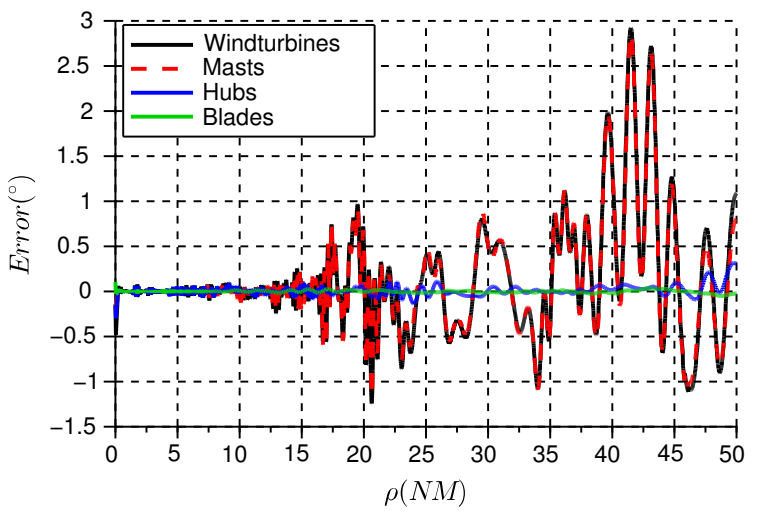

Figure 8: Simulated VOR error $\left(^{\circ}\right)$ due to the wind turbine hubs (blue), blades (black), and masts (green) on the radial $\varphi=-10^{\circ}$.

The blades and the hubs add less than $0.1^{\circ}$ to $0.3^{\circ}$ error each. This is very low compared to the total error. So the difference between the two measurement campaigns (masts only and complete wind turbines) is mainly due the differences between the two flight trajectories during the two measurement campaigns.

This also shows that to study the effect of additional wind turbines in the same zone, modelling the masts only would give a good approximation of the total error. Note that this conclusion is only valid for this type of wind turbine and on that trajectory. More simulations would be necessary to extend the validity of this statement.

In conclusion, the simulation method presented in this paper allows to discriminate the contributions to the VOR error of the different scatterers and their inner parts. For instance, it is shown here that far from the VOR, the masts are the main contributors to the error.

\section{CONCLusion}

The simulation method presented here to predict the VOR error due to large scatterers is based on an hybridisation between parabolic equation and physical optics. A processing step to take into account the VOR receiver is also used. In this paper, this method has been applied to wind turbines. A validation with in-flight measurements around a conventional
VOR in Boulogne-sur-Mer and nine wind turbines nearby has been performed.

The simulator ability to compute the VOR error due to complex obstacles such as wind farms with a great accuracy has been shown. This simulator can also discriminate the contributions of the different obstacles and their different parts to the VOR error.

The simulator can be used before flight inspections. A simulation of the VOR error all around the VOR indicates the radials to consider if one wants to measure the maximum error during a flight inspection. It can also be used beforehand to approve or turn down a wind farm building project. Note that the reasonable simulation time allows to study several scenarii for a single project.

\section{ACKNOWLEDGMENT}

The authors would like to thank the French Air Navigation Service Provider (DSNA/DTI) for the funding.

\section{REFERENCES}

[1] ICAO, "European guidance material on managing building restricted areas," ICAO, Tech. Rep. EUR DOC 015, September 2009.

[2] S. Odunaiya and D. Quinet, "Calculations and analysis of signal processing by various navigation receivers architectures," The 23rd Digital Avionics Systems Conference, vol. 1, pp. 1.D.1-11-13 Vol.1, Oct 2004.

[3] F. P. Fontan, D. Marote, A. Mayo, B. Sanmartin, A. Castro, and J. J. Navarro, "Assessing multipath induced errors in VOR systems using ray-tracing techniques in combination with detailed terrain databases," in International Flight Inspection Symposium (14th IFIS). 14th International Flight Inspection Symposium, June 2006, pp. 91-96.

[4] I. Gonzalez, L. Lozano, J. Gomez, A. Tayebi, I. Etayo, and M. Catedra, "Analysis of the scattering field of wind turbine using rigorous and asymptotic techniques," in Proceedings of the Fourth European Conference onAntennas and Propagation (EuCAP), April 2010, pp. 1-4.

[5] C. Morlaas, A. Chabory, and B. Souny, "Propagation model for estimating VOR bearing error in the presence of windturbines - hybridation of parabolic equation with physical optics," in Proceedings of the Fourth European Conference on Antennas and Propagation (EuCAP), April 2010, pp. 1-5.

[6] A. Calo Casanova, P. Pathak, and M. Calvo Ramon, "Modeling windmill interference via hybrid parabolic equation and equivalent current approximation methods," in International Conference onElectromagnetics in Advanced Applications (ICEAA), Sept. 2011, pp. 275-278.

[7] A. Calo Casanova, M. Ramon, L. de Haro y Ariet, and P. BlancoGonzalez, "Wind farming interference effects," in International MultiConference on Systems, Signals and Devices, July 2008, pp. 1-6.

[8] D. de la Vega, C. Fernandez, O. Grande, I. Angulo, D. Guerra, Y. Wu, P. Angueira, and J. Ordiales, "Software tool for the analysis of potential impact of wind farms on radiocommunication services," in IEEE International Symposium on Broadband Multimedia Systems and Broadcasting (BMSB), June 2011, pp. 1-5.

[9] J. A. Fernandes, L. M. Correia, C. Alves, L. Pissarro, and M. Teixeira, "Assessment of wind turbines generators influence in VOR aeronautical navigation systems," in IEEE International Symposium on Antenna and Propagation, July 2014.

[10] G. D. Dockery and J. R. Kuttler, "An improved impedance-boundary algorithm for Fourier split-step solutions of the parabolic wave equation," IEEE Transactions on Antennas and Propagation, vol. 44, pp. 1592-1599, 1996.

[11] S. W. Lee and R. Mittra, "Fourier transform of a polygonal shape function and its application in electromagnetics," IEEE Transactions on Antennas and Propagation, vol. 31, pp. 99-103, 1983.

[12] L. Claudepierre, R. Douvenot, A. Chabory, and C. Morlaas, "A deterministic VOR error simulation method - Application to windturbines," IEEE Transactions on Aerospace and Electronic Systems, 201X, submitted, title subject to modification. 
[13] _ - "Influence of the lightning protection of blades on the field scattered by a windturbine," in Proceedings of the 9th European Conference on Antennas and Propagation (EuCAP), April 2015, pp. 1-5.

[14] _ "Assessment of the shadowing effect between windturbines," in Proceedings of the 9th European Conference on Antennas and Propagation (EuCAP), April 2015, pp. 1-5. 